
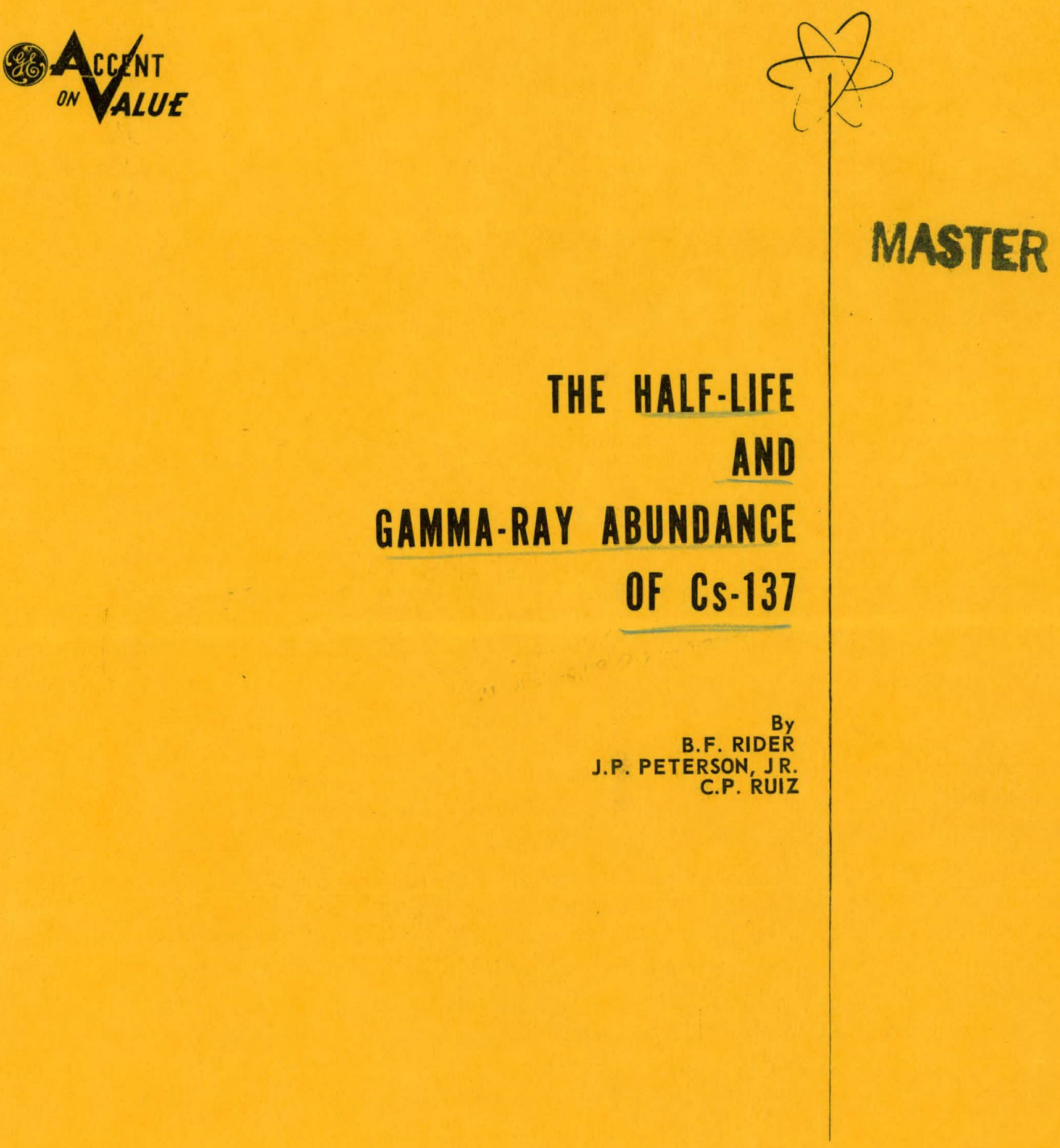

VALLECITOS ATOMIC LABORATORY

GENERAL ELECTRIC

ATOMIC POWER EQUIPMENT DEPARTMENT

SAN IOSE, CALLFORNIA 


\section{DISCLAIMER}

This report was prepared as an account of work sponsored by an agency of the United States Government. Neither the United States Government nor any agency Thereof, nor any of their employees, makes any warranty, express or implied, or assumes any legal liability or responsibility for the accuracy, completeness, or usefulness of any information, apparatus, product, or process disclosed, or represents that its use would not infringe privately owned rights. Reference herein to any specific commercial product, process, or service by trade name, trademark, manufacturer, or otherwise does not necessarily constitute or imply its endorsement, recommendation, or favoring by the United States Government or any agency thereof. The views and opinions of authors expressed herein do not necessarily state or reflect those of the United States Government or any agency thereof. 


\section{DISCLAIMER}

Portions of this document may be illegible in electronic image products. Images are produced from the best available original document. 


\section{ATOMIC POWER EQUIPMENT DEPARTMENT \\ GENERAL ELECTRIC}

SAN JOSE, CALIFORNIA

TECHNICAL INFORMATION SERIES title page

\begin{tabular}{|c|c|}
\hline AUTHOR Rider $\quad$ SUBJECT & $\begin{array}{l}\text { GEAP }-4008 \\
\text { NO. } 62 \mathrm{APE} 5 \\
\end{array}$ \\
\hline J..P. Peterson, Jr. Cs-137 Half-Lif & DATE June 1, 1962 \\
\hline $\begin{array}{l}\text { ThTLE Half-Life and Gamma-Ray } \\
\text { The }\end{array}$ & GE CLASS \\
\hline 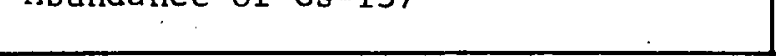 & GOVT. CLASS None \\
\hline $\begin{array}{l}\text { REPRODUCIBLE COPY FILED AT } \\
\text { TECHNICAL PUBLICATIONS UNIT, } \\
\text { APED, SAN JOSE, CALIFORNIA }\end{array}$ & NO. PAGES \\
\hline
\end{tabular}

The half-1ife of cesium-137 has been determined to be $29.2 \pm 0.3$ years by an a.11 mass spectrometric method.

The abundance of the $662 \mathrm{Kev}$ gamma-ray in the decay scheme of Cs-137 was found to be $0.82 \pm 0.03$ per beta. disintegration.

In the course of the work, the isotopic distribution of natural barium was determined with improved accuracy to be $(72.11 \pm 0.06) \% 138,(11.18 \pm 0.05) \% 137,(7.77 \pm$ $0.02) \% 136,(6.42 \pm 0.03) \% 135,(2.33 \pm 0.02) \% 134$, $(0.091 \pm 0.003) \% 132$, and $(0.098 \pm 0.002) \% 130$.

By cutting out this rectangle and folding on the center line, the above information can be fitted into a standard card file.

For llst of contents-diuwings, photos, atc. and for distribution seo next page (FN-610-2)

JOB NUMBER $721-$ TIO -2

INFORMATION PREPARED FOR GENERAL ELECTRIC CO.

TESTS MADE BY T. T. P.eer

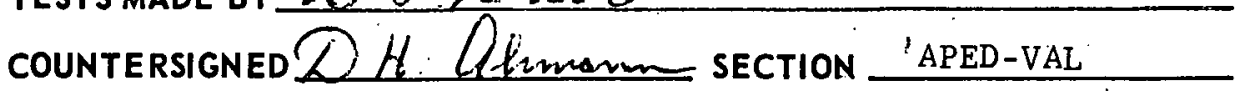
BUILDING AND ROOM NO. 103-228 LOCATION Pleasanton, Calif. 


\section{DISCLAIMER OF RESPONSIBILITY}

This report was prepared as an account of research and develop. ment work performed by General Electric Company. It is being made available by General Electric Company without consideration in the interest of promoting the spread of technical knowl. edge. Neither General Electric Company nor the individual author: A. Makes any warranty or representation, expressed or implied, with respect to the accuracy, completeness, or usefulness of the information contained in this report, or that the use of any information disclosed in this report may not infringe privately owned rights; or

B. Assumes any responsibility for liability or damage which may result from the use of any information disclosed in this report. 


\section{DISTRIBUTION}

D. H. Ahmann

H. W. A1 ter

J. 0. Arterburn

J. R. Asay

R. F. Royle

F. J. Brutschy

L. P. Bupp

J. G. Carver

R. W. Darmitze1.

W. E. Duffy.

S. C. Furman

D. W. Gaylor

J. M. Gerhart

R. S. Gilbert

J. F. Hanus

E. L. Kramer

P. W. Mathay.

W. R. Morgan

R. C. Nèlson

R. N. Osborne

J, P., Peterson, Jr.

L. L. Reed

B. F. Rider: (50)

C. P. Ruiz

J. L. Russell, Jr.

W. W. Sabọ1

D. L: West

D. L. Limmerman

GE-TIS

VAL Library

APED Library

AEC-DTIE
(2)

(3).

(5)

(3) + Masters 
Page No.

\section{SECTION}

I. 'INTRODUCTION

II. SUMMARY 2

III. EXPERIMENTAL AND RESULTS . 5

A. Ion Exchange Studies 5

B. Isotopic Dilution Techniques 7

C. ' Mass.Spectrometry . 8

D. $\therefore$ Measurement of $\mathrm{Ba}-137$ Daughter Growth 11

E. Calculation of Half-Life 13

F. . Betermination of Gamma Ray Abundance of Cs-137 14

İV. CONCLUSIONS $\quad \ldots$

$\begin{array}{llll}\text { V. ACKNOWLEDGEMENT _ . } \quad 18 & 18\end{array}$

\section{APPENDIX}

I. Definition of Symbols Used 19

II. Calculation of the Total Number of Cs-137 Atoms . 20 in the Master Solution

III. Ca1culation of Ba-138 Tracer Added to the Master 22

IV. : Derivation of Equations Used to Calculate Atoms ! ' 25

V. The Constant Ratios Used in Calculations in 32 Appendix IV

VI. The Ba-137 Growth Line and. Wcighted Least Squares 33 Solution of its Slope

VII. Calculation of Gamma-Ray Abundance in The Decay of 38 Cs -137 
Page No.

Figure 1. Growth of $\mathrm{Ba}-137$

4

Figure 2. Barium and Cesium Elution

6

\section{LIST OF TABLES}

Table I. Impurity Analyses of Primary Cesium 9 and Barium Standards

Table II. Isotopic Analysis of Natural Barium and Enriched Ba-138 Used in This. Study

Table III. Nuclear Chicago Cs-137 Standards Used to Calculate $662 \mathrm{Kev}$ Gamma Ray Abundance in C.s -137

'Table IV. Data Calculated for Ba-138 Spike Concentration 


\section{ABSTRACT}

The half-1ife of cesium-137 has been determined to be $29.2 \pm 0.3$ years by an a11 mass spectrometric method.

The abundance of the $662 \mathrm{Kev}$ gamma-ray in the decay scheme of $\mathrm{Cs}-137$ was found to be $0.82 \pm 0.03$ per beta disintegration.

In the course of the work, the isotopic distribution of natural barium was determined with improved accuracy to be $(72.11 \pm 0.06) \% 138,(11.18 \pm 0.05) \% 137,(7.77 \pm 0.02) \% 136$, $(6.42 \pm 0.03) \% 135,(2.33 \pm 0.02) \% 134,(0.091 \pm 0.003) \% 132$, and $(0.098 \pm 0.002) \% 130$. 


\section{SECT:ION I}

\section{TNTRODUCT ION}

The nuclide $\mathrm{Cs}-137$ is a fission product commonly used for measurement of uranium burnup in irradiated uranium fuel by the fission product to uranium ratio method. In the application of this method, the largest single error introduced in the measurement of burnup is the uncertainty in the half-life of $\mathrm{Cs}-137^{(1)}$. The $\mathrm{Cs}-137$ half-life has been reported from specific activity measurements to be $28.4 \pm 1.4^{(1)}, 26.6 \pm 0.4^{(2)}$, $30.0 \pm 0.4^{(3)}, 28.6 \pm 1^{2(4)}, 32.6 \pm 1.6^{(5)}, 27^{(6)}$ and $29 \pm 1$ years ${ }^{(7)}$, and from mass spectrometric measurements to be $30.4 \pm 0.4$ years ${ }^{(8)}$.

Because of the uncertainty in this value and its importance in nuclear fuel burnup analysis, a reinvestigation was undertaken to obtain a more accurate value using the mass spectrometric method. 


\section{SECTION II}

\section{SUMMARY}

The ha.lf-1ife of $\mathrm{Cs}-137$ has been determined from the rate of formation of daughter $\mathrm{Ba}-137$ in a measured amount of $\mathrm{Cs}-137$ by isotopic dilution mass spectrometry. Only one such measurement, $30.4 \pm 0.4$ years ${ }^{(8)}$, has been previously reported.

The barium daughters initially present in a $200 \mathrm{mc}$. source of fission product cesium were removed by Dowex-50 cation exchange techniques. After sampling for mass analysis, the cesium eluate was added to a polyethylene flask containing accurately weighed aliquots of standardized Cs-133 and $98.6 \%$ enriched Ba-138 spike solutions.

The Cs-133 solution was a primary standard prepared by weight from spectrographically pure natural $\mathrm{CsCl}$. The $\mathrm{Ba}-138$ was standardized by isotopic dilution with a primary standard prepared by weight from analyzed C.P. natural $\mathrm{BaCl}_{2} \cdot 2 \mathrm{H}_{2} \mathrm{O}$. By isotopic dilution, the initial number of $\mathrm{Cs}-137$ and $\mathrm{Ba}-138$ atoms in the flask were known to a standard deviation of $0.68 \%$ and $0.42 \%$ respectively.

To. establish the rate of growth of $\mathrm{Ba}-137$, small samples of the master solution were analyzed for barium isotopic abundances over a. period of 100 days. The barium was freed of cesium by cation exchange prior to analysis. Accurately known sample volumes or chemical yields were not necessary because the initial solution contained the enriched Ba-138 spike.

Two solid emission mass spectrometers, a two-stage magnetic analyzer, using an electron multiplier detector and a single-stage magnetic analyzer with a Faraday cage detector and vibrating reed electrometer, were used to determine the mass ratios. 
In barium samples, the mass 133 position was used to monitor for Cs-137 contamination, which was found to be negligibly small. The mass-136 position was used to correct for natural barium contamination. Smal1 corrections were applied for $\mathrm{Ba}-137$. content of the $\mathrm{Ba}-138$ spike and the effect of $\mathrm{Cs}-137$ decay.

The.slope of the Ba-137 growth curve (Figure 1) was determined to a standard deviation of $0.50 \%$ from a weighted least squares analysis of the data. From these data, the half-life was determined to be $29.2 \pm 0.3$ years at one standard deviation. This value is consistent with the average of the values referenced and has a smaller uncertainty than any of the previous measurements.

The gamma-ray abundance of $\mathrm{Cs}-137$ was measured by gamma counting ampoules with a known number of atoms of $\mathrm{Cs}-137$ on a sodium iodide gamma spectrometer calibrated with Nuclear Chicago Standard Cs-137 sources. The abundance of the $662 \mathrm{Kev}$ gamma ray in the decay scheme of Cs-137 was found to be $0.82 \pm 0.03$ per beta disintegration. 


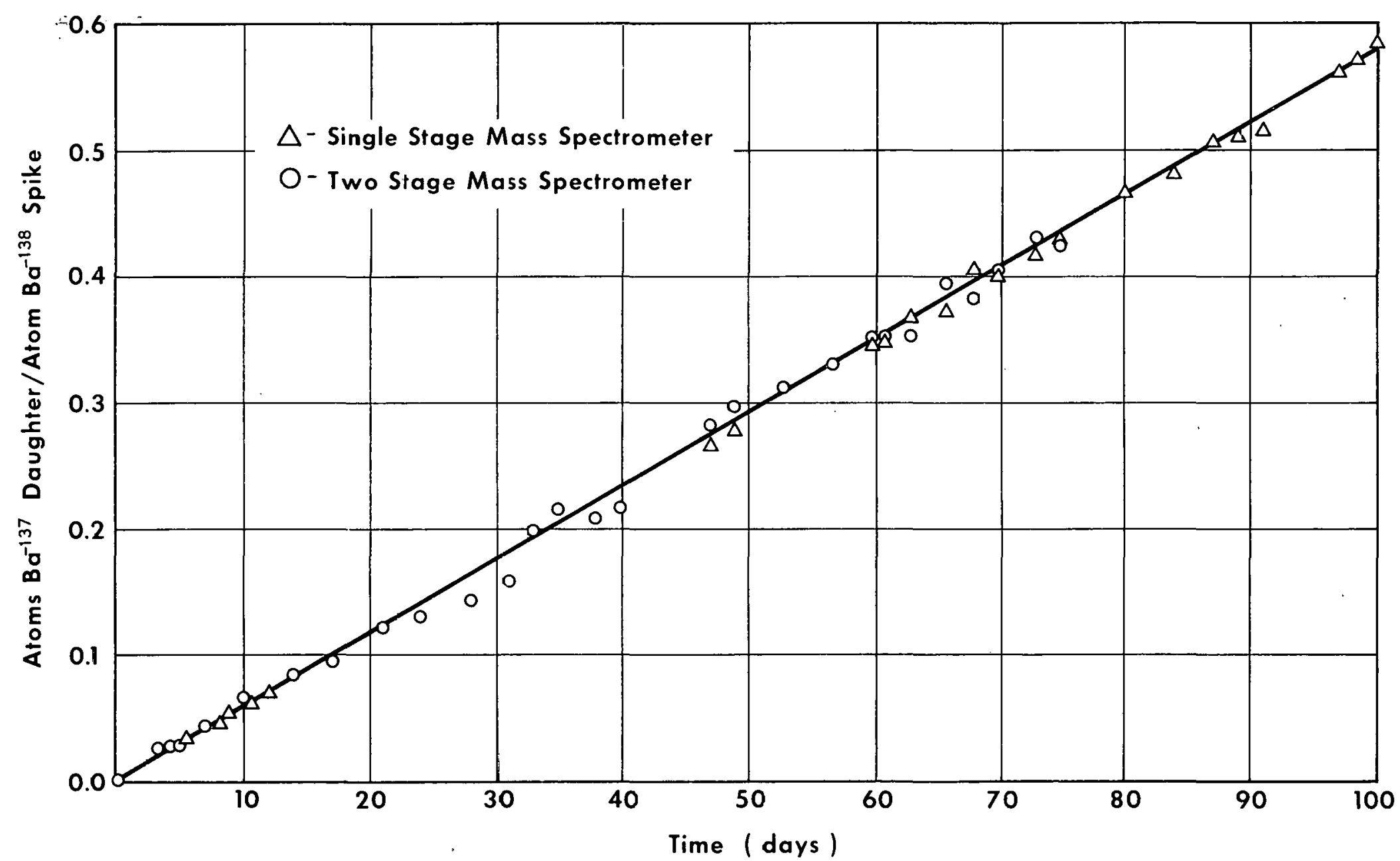

Figure 1. RATE OF GROWTH OF $\mathrm{Ba}^{-137}$ 


\section{EXPERIMENTAL AND RESULTS}

A description of the experimental work performed to measure the $\mathrm{Cs}-137$ half-life can be logically arranged into the following sections: (a) development of an ion exchange separations scheme for isolating barium daughters from a Cs-137 sample in preparation for mass spectrometry; (b) measurement of the number of parent $\mathrm{Cs}-137$ atoms and the number of Ba-138 tracer a.toms." present in the stock solution by isotopic dilution mass spectrometry; (c) description of the mass spectrometers used in this work; (d) measurement of the growth of $\mathrm{Ba}-137$ atoms with respect to the $\mathrm{Ba}-138$ spike as a function : of time; (e) calculation of $\mathrm{Cs}-137$ half-life; and finally, (f) measurement of the gamma ray abundance of $\mathrm{Cs}-137$. Each section will be described in some detail.

\section{A. Ion Exchange Studies}

The ion exchange behavior of barium and cesium on cation resin in $\mathrm{HCl}$ systems was investigated with small columns of $2.5 \mathrm{~mm}$ I.D. containing $10 \mathrm{~mm}$ length of $200-400$ mesh Dowex-50 x 8 . The volume of resin per column was about $50 \mu$ liters. The Cs-137 activity was loaded on the column and eluted with $1 \underline{M} \mathrm{HCl}$ at a flow rate of $1 \mathrm{cc} / \mathrm{min}$. The specific activity of each four-drop fraction (18 drops per $\mathrm{ml}$ ) is plotted in Figure 2. After 52 drops, no cesium activity above background could be detected.

A similar study was performed with Ba-139 tracer using 1 M HCl as the eluant (Figure 2). Very 1ittle barium was eluted in the first 40 drops (18 drops per $\mathrm{m} 1$ ). By drop 60 , about $2 \%$ of the barium activity was lost from the column, and by drop 80 , barium losses totaled $8 \%$. After drop 80 , the eluant was changed to $6 \underline{\mathrm{M}} \mathrm{HCl}$ to elute the barium. Over $80 \%$ of the barium was eluted in the first 10 drops of $6 \mathrm{M} \mathrm{HCl}$. 


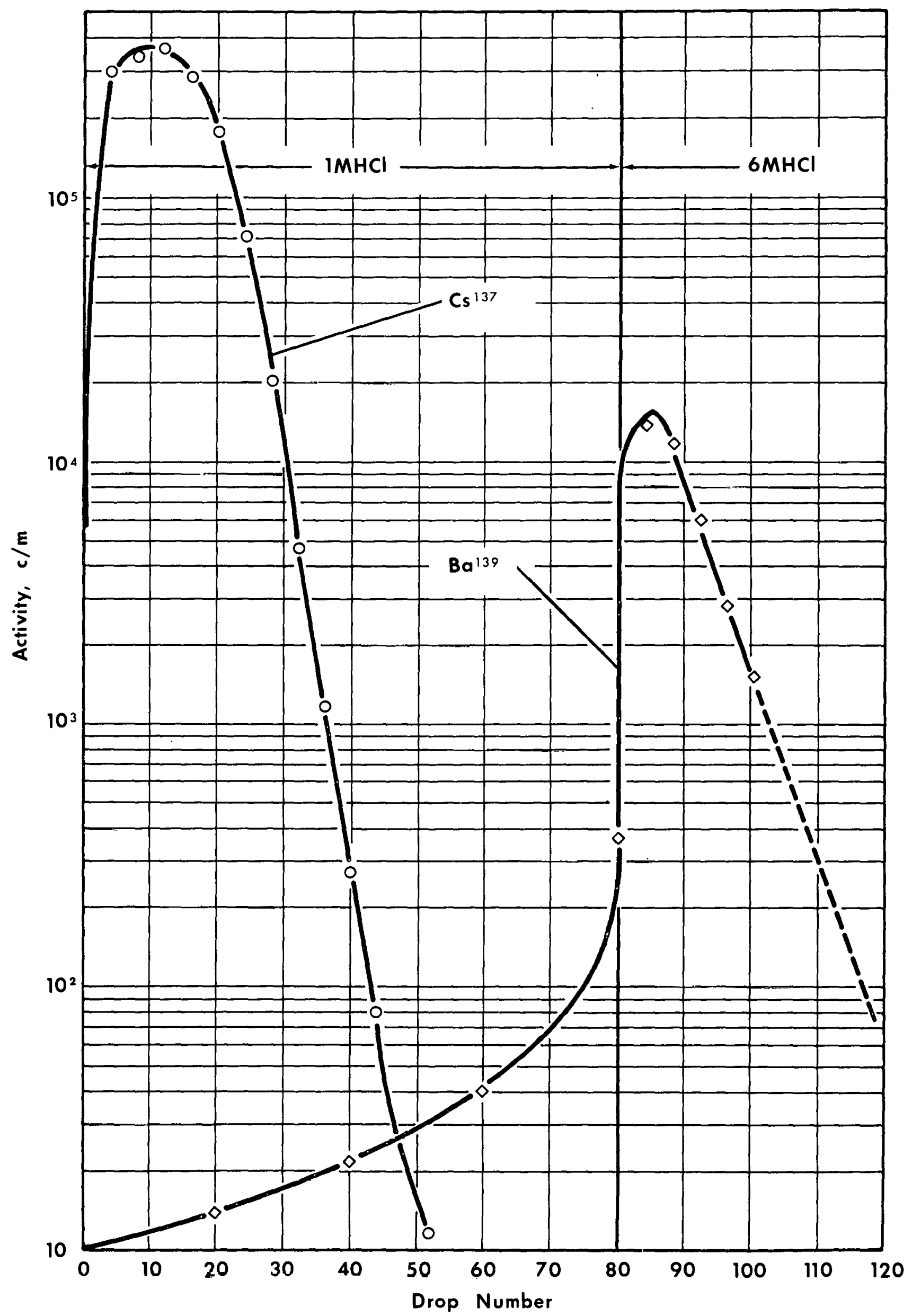

Figure 2. CESIUM AND BARIUM ELUTION

$2.5 \mathrm{~mm} \times 10 \mathrm{~mm}$ Column of Dowex $-50 \times 8$ (200-400 mesh) 
Based on these observations, the following procedure was adopted for the purification of barium daughters from $\mathrm{Cs}-137$. After loading up to 10 drops of $\mathrm{Cs}-137$ in $1 \underline{\mathrm{M} \mathrm{HCl}}$, the column was washed with 80 drops of $1 \mathrm{M} \mathrm{HCl}$ to remove all Cs-137. The barium daughters were then eluted with 10 drops of $6 \underline{\mathrm{M}} \mathrm{HCl}$, evaporated to dryness, and mounted with $0.05 \underline{\mathrm{M}} \mathrm{HC} 1$ on $a$ rhenium filament for mass analysis.

Every effort was made to minimize natural barium contamination. Constant boiling (6M) HCl was distilled and stored in leached polyethylene bottles. The $1 \underline{M}$ HCl was prepared by dilution of this acid with deionized distilled water. The glass columns, pipets, and test tubes used to collect the eluate fractions were boiled in $6 \mathrm{M} \mathrm{HCl}$ and rinsed in deionized distilled water. Any natural barium contained in the resin was removed by elution with ' 40 column volumes of $6 \underline{\mathrm{M}} \mathrm{HCl}$ for each column; this was followed by conditioning with 1 M HCl prior to sample loading.

B. Isotopic Dilution Techniques

Having established an ion exchange separation procedure for separation of cesium and barium, a 200 millicurie batch of ORNL Cs-137 was passed through a large Dowex-50 column and eluted with twenty column volumes of 1 M HCl in order to strip out all barium daughters, present. The resulting Cs-137 solution was mass analyzed for a total of 47 mass spectrum scans on 3 filaments. The atom ratios of 133/137 and 133/135 were observed to be $1.246 \pm 0.006$ and $2.505 \pm 0.009$, respectively. For consistency, all errors quoted are at one standard deviation. This solution was added to a leached polyethylene bottle containing a teflon covered stirring bar plus weighed aliquots of standardized $\mathrm{Cs}-133$ and enriched $\mathrm{Ba}-138$ solutions and was thoroughly stirred to achieve isotopic exchange. These two isotopic diluents were selected because they were available in high purity.

The Cs-133 solution was a primary standard prepared by weight from chemically pure $\mathrm{CsC} 1$. The most common impurity in this chemical is usually rubidium. The rubidium content of the salt was therefore 
analyzed flame photometrically and found to be $0.02 \%$ by weight. The salt was then analyzed by emission spectroscopy to be $99.95 \%$ pure. The impurities found are listed in Table $I$. The isotopic analysis of the cesium standard was verified to be $100 \%$ Cs -133 with other mass positions from 129 to 138 less than $0.01 \%$ of the 133 peak. The analysis of the master Cs-137 stock solution isotopically diluted with Cs-133 standard was found from 183 scans on ten filaments. The observed atom ratios of $133 / 137$ and $133 / 135$ were $50.83 \pm 0.32$ and $104.9 \pm 0.72$ respectively. Appendix II shows the calculation of the number of Cs-137 atoms present initially in the master solution to be $1.044_{4} \times 10^{19} \pm 0.68 \%$.

The Ba-138 standard solution was standardized by isotopic dilution with a primary standard prepared by weight from C.P. $\mathrm{BaCl}_{2} \cdot 2 \mathrm{H}_{2} \mathrm{O}$ analyzed by the $\mathrm{BaSO}_{4}$ gravimetric procedure to be $99.88 \%$ pure. The principal impurities present are listed in Table $I$. The mass analysis of natural barium was obtained from 86 scans on 8 filaments and the mass analysis of the enriched Ba-138 was obtained from 63 scans on 5 filaments. Both analyses are summarized in lable II. Four weighed aliquots of the enriched Ba-138 standard solution were isotopically diluted with weighed portions of the natural barium standard solution. The calculations of the $\mathrm{Ba}-138$ tracer atoms in the master solution as calculated from 129 scans on 7 filaments are shown in Appendix III. A weighted average of al1 determinations show $1.175{ }_{2} \times 10^{17} \pm 0.43 \%$ atoms $\mathrm{Ba}-138$ tracer atoms present in the master solution.

\section{Mass Spectrometry}

All isotopic analyses of cesium samples, and natural enriched barium samples, before and after isotopic dilution, as well as most of the Ba-137 daughter growth samples, were performed on single-stage solid emission mass spectrometer employing a Faraday cage detector and vibrating reed electrometer. This instrument makes use of a secondary emission suppressor and measures only primary beam current. For this reason, and because ions are accelerated at constant potential while mass positions are sr.anned magnetical1y, mass discrimination should not 
TABLE I

Impurity Analyses of Primary Cesium and Barium Standaräs

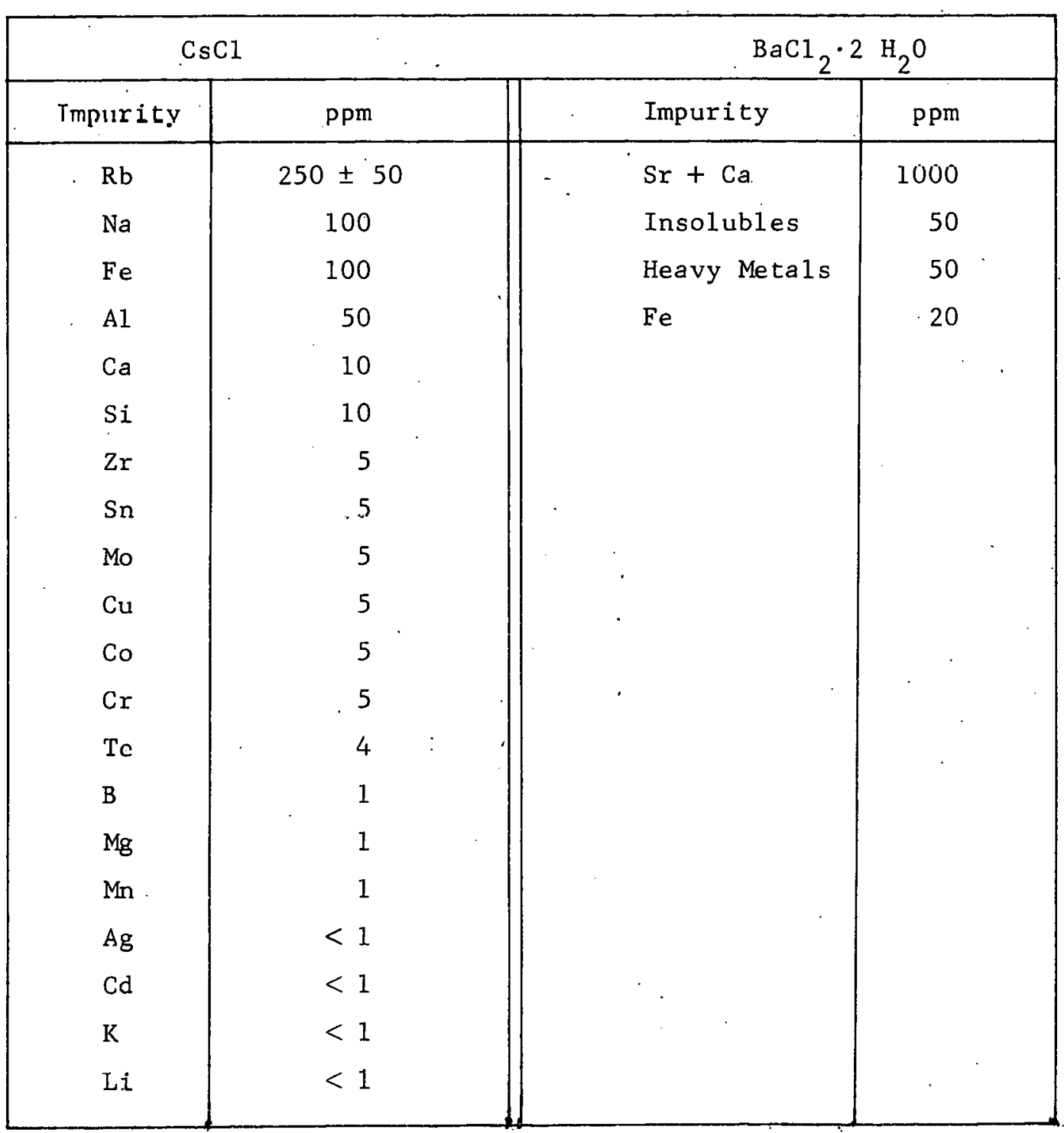


TABLE II

Isotopic Analysis of Natural Barium and

Enriched Ba-138 Used in This Study

\begin{tabular}{|l|c|c|}
\hline Isotope & Natural Ba, Atom $\%$ & Enriched Ba-138, Atom \% \\
\hline $\mathrm{Ba}-138$ & $72.11 \pm 0.06$ & $98.56 \pm 0.01$ \\
$\mathrm{Ba}-137$ & $11.18 \pm 0.05$ & $1.24 \quad \pm 0.01$ \\
$\mathrm{Ba}-136$ & $7.77 \pm 0.02$ & $0.136 \pm 0.004$ \\
$\mathrm{Ba}-135$ & $6.42 \pm 0.03$ & $0.052 \pm 0.001$ \\
$\mathrm{Ba}-134$ & $2.33 \pm 0.02$ & $0.0134 \pm 0.0004$ \\
$\mathrm{Ba}-132$ & $0.091 \pm 0.003$ & $0.00035 \pm 0.00004$ \\
$\mathrm{Ba}-130$ & $0.098 \pm 0.002$ & $0.00054 \pm 0.00005$ \\
\hline
\end{tabular}


occur nor was it observed. Ba-137 growth samplès were chemically processed almost daily for the first two weeks and approximately every other day thèreafter.

Initially, Ba-137 growth samples were analyzed on a more sensitive twostage magnetic analyzer using an electron multiplier detector because of the greater sensitivity of this instrument. Ihis instrument uses a fixed magnetic field while the mass positions are scanned electrostatically. Mass discrimination occurs at the first dynode electron multiplier due to variation in secondary emission with ion velocity. This mass discrimination was measured and a correction made.

\section{Measurement of $\mathrm{Ba}-137$ Daughter Growth}

The growth of $\mathrm{Ba}-137$ daughter was observed by noting the increase in the mass $137 / 138$ ratio with time. In order to avoid interference in the mass 137 position from (a) Cs-137, (b) Ba-137 from natural barium contamination, and (c) Ba-137 traces in the $\mathrm{Ba}-138$ spike and in order to avoid interference from natural $\mathrm{Ba}-138$ contamination in the mass 138 position, an equation was developed (Appendix IV) to allow for correction of each of these interferences by making use of the 133 mass position as a cesium indicator and the 136 mass position as an indicator for naturai barium contamination. The final equation is expressed:

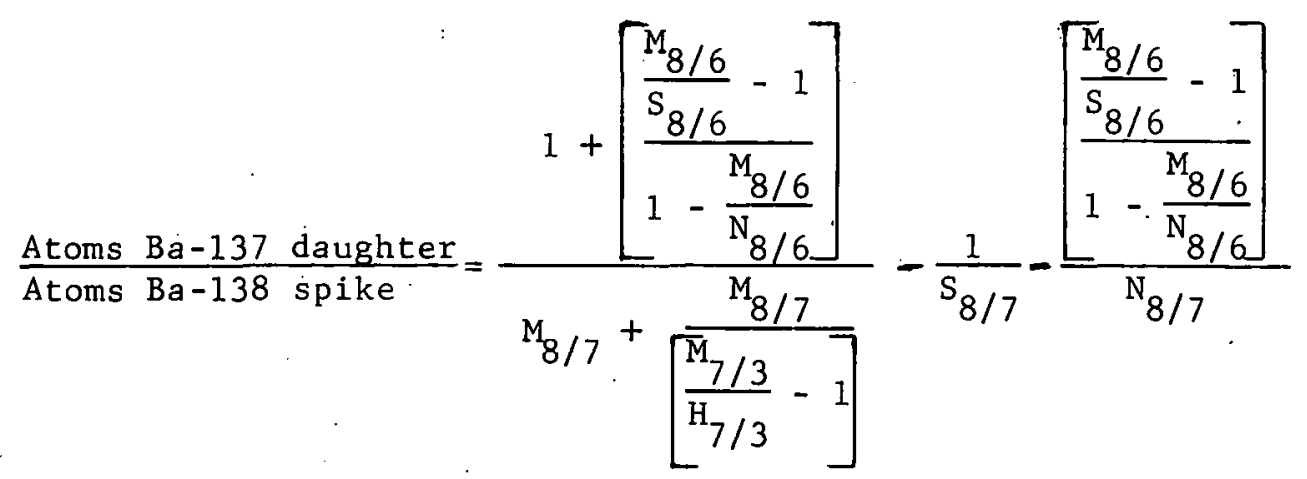

where the symbols are defined in Appendix I. 
In practice, only four of the fifty-four data points showed much Cs-133 present and the correction in these cases amounted to less than $1 \%$. Natural barium contamination was larger, however, and was in the order of $13 \%$ correction at 100 days of growth and was progressively larger near the origin. Care was taken to propagate into the final 137/138 ratios errors of each value substituted in the equations.

A. plot of the Ba-137 daughter atoms per atom of Ba-138 spike as a function of time in days is found in Figure 1. The deviation of the points about the line evident between 20 and 40 days was of concern so that attempts were made to verify analysis of Ba-137 daughter growth samples on the less sensitive single stage instrument. This instrument showed sensitivity for barium much greater than anticipated and samples at 47 and 49 days ran well on both instruments. As a result, all samples from 60 to 75 days were analyzed on both instruments. Values obtained on the single-stage instrument agreed with those obtained on the two-stage instrument, exhibited a smaller scan to scan and point to point variation and eliminated the need for mass discrimination corrections.

After 75 days, a.1 further measurements werc made on the single-stage instrument because of its excellent performance. Five samples which had been set aside from the period of 6 to 12 days growth were also analyzed on this instrument. In addition, the final sample at 100 days was analyzed in triplicate because of the importance of last point in determination of the slope and to obtain a further check on the filament to filament variation.

The data in Figure 1 represent the growth curve for a stable daughter in a radioactive parent and do not form a straight line. Daughter growth is proportional to $\left(1-e^{-\lambda t}\right)$. However, each point has been multiplied by the factor $\left(\frac{\lambda t}{1-e^{-\lambda t}}\right)$ to correct for $\mathrm{Cs}-137$ decay and obtain the $137 / 138$ ratio which would be present if no decay of parent had occurred. The plot thus corrected is a linear function with time. 
The equation for this line was found by least squares treatment (Appendix VI). The general equation is of the form $y=a x+b$ where $y$ is the atoms Ba-137 daughter per atom Ba-138 spike, $x$ is the time of growth in days, $a$ is the slope, and $b$ is the $y$ intercept. By assuming no error in $x$ (the time scale) since all time measurements were easily measured to $1 / 1000$ of a day, and weighting values of $y$ as the reciprocal of a function of the error in each value, the equation becomes

$$
y=\left(0.00578_{7} \pm 0.00002_{9}\right) x-\left(0.000_{5} \pm 0.001_{6}\right) .
$$

This weighted treatment of the data was adopted to obtain minimum error in the slope after it was demonstrated that weighted treatment when compared with unweighted treatment of data from each individual mass spectrometer did not differ statistically from spectrometer to spectrometer or from weighted to unweighted treatment.

From the measurement made, it was possible to determine the half-life of Cs-137 and by some additional gamma. measurements, the abundance of the 662 Kev gamma-ray per beta disintegration.

\section{E. Calculation of Half-Life}

The half-life, $T_{\frac{1}{2}}$, is related to the decay constant, $\lambda$, by the expression

$$
\mathrm{T}_{\frac{1}{2}}=\frac{0.69315}{\lambda}
$$

Disintegration rate or activity is related to $\lambda$ by the expression

$$
\frac{-{ }^{-d N} \mathrm{Cs}_{-137}}{\mathrm{dt}}=\lambda \mathrm{N}_{\mathrm{Cs}-137}
$$

Solving the equation for $\lambda$, one obtains the expression

$$
\lambda=\frac{-\mathrm{dN}_{\mathrm{Cs}-137^{/ d t}}}{\mathrm{~N}_{\mathrm{Cs}-137}}
$$


However, disintegration rate is equal to the atoms of Ba-137 formed per unit time. This quantity is the slope, a, of the equation for the growth line (Appendix.VI) multiplied by the atoms of Ba-138 spike, $\mathrm{N}_{\mathrm{Ba}-138 \text {. Therefore }}$

$$
\lambda=a\left[\frac{\mathrm{N}_{\mathrm{Ba}-138}}{\mathrm{~N}_{\mathrm{Cs}-137}}\right] .
$$

Since $\mathrm{N}_{\mathrm{Ba}-138}$ spike is $1.175_{2} \times 10^{17} \pm 0.43 \%$ (Appendix III) and $\mathrm{N}_{\mathrm{Cs}-137}$ is $1.044_{4} \times 10^{19} \stackrel{-1}{ } 0.68 \%$ (Appendix II) and "a" is calculated to be $0.00578 \pm 0.50 \%$ (Appendix VI), the value of $\lambda$ becomes $6.51 \times 10^{-5}$ $\pm 0.96 \%$ days $^{-1}$ corresponding to a half-life of $29.2 \pm 0.3$ years.

\section{F. Determination of Gamma Ray Abundance of Cs-137}

Within two hours of the preparation of the master Cs-137 stock solution, seven weighed aliquots were sealed into glass ampoules similar to Nuclear Chicago Cs-137 standards with respect to liquid volume, glass dimensions, and thickness. Since the number of Cs-137 atoms in the master stock solution were known to an accuracy of $0.68 \%$ and each of these ampoules represent carefully measured aliquots, each of these ampoules serve as an accurately known number of Cs-137 atoms.

Appendix VI shows 69 comparisons that were made between these ampoules and two Nuclear Chicago Cs-137 standards. Both samples and standards were corrected for their Cs-134 contents. The Cs-137 atom concentration in the Nuclear Chicago standards were determined to $1 \%$. These values are given in line 6 of Table III. It should be noted that the Cs-137 atoms/ml are more accurately known than the certified gamma activities of the standards.

If the atoms $/ \mathrm{ml}$ of $\mathrm{Cs}-137$ in line 6 are multiplied by $\lambda$ in minute ${ }^{-1}$ corresponding to 29.2 year half-life, one obtains the $\mathrm{d} / \mathrm{m} / \mathrm{ml}$ and finally $\mathrm{d} / \mathrm{s} / \mathrm{ml}$ on line 10 . By dividing line 5 by 1 ine 10 , one obtains a gamma abundance of 0.82 gamma photons at $662 \mathrm{Kev}$ per disintegration on 1 ine 11 . 
TABLE III

Nuclear Chicago Cs-137 Standards

Used to Calculate 662 Kev Gamma Ray Abundance in Cs-137

\begin{tabular}{|c|c|c|c|c|c|}
\hline & Item & Batch 非 1 & & Batch 非2 & \\
\hline 1. & Date & $2-27-59$ & & $8-1-61$ & \\
\hline 2. & $\gamma / \mathrm{s} / \mathrm{ml}$ tota 1 & $6.33 \times 10^{5}$ & $\pm 3 \%$ & $9.20 \times 10^{5}$ & $\pm 3 \%$ \\
\hline 3. & $\mathrm{\gamma} / \mathrm{s} / \mathrm{ml} 600 \mathrm{Kev} \mathrm{Cs}-134$ & $-0.04 \times 10^{5}$ & $\pm 10 \%$ & $-0.18 \times 10^{5}$ & $\pm 10 \%$ \\
\hline 4. & $\mathrm{y} / \mathrm{s} / \mathrm{m1} 800 \mathrm{Kev} \mathrm{Cs}-134$ & $-0.04 \times 10^{5}$ & $\pm 10 \%$ & $-0.18 \times 10^{5}$ & $\pm 10 \%$ \\
\hline 5 . & $y / s / m 1662 \mathrm{Kev} C s-137$ & $6.25 \times 10^{5}$ & $\pm 3 \%$ & $8.84 \times 10^{5}$ & $\pm 3 \%$ \\
\hline 6. & $\begin{array}{l}\text { Atoms } / \mathrm{m} 1 \mathrm{Cs}-137 \text { on } \\
\text { date in Iine } 1 \text { above }\end{array}$ & $1.01 \times 1.0^{15}$ & $\pm 1 \%$ & $1.43 \times 10^{15}$ & $\pm 1 \%$ \\
\hline 7. & $x \lambda \min ^{-1}$ & $4.52 \times 10^{-8}$ & $\pm 1 \%$ & $4.52 \times 10^{-8}$ & $\pm 1 \%$ \\
\hline 8. & $=\mathrm{d} / \mathrm{m} / \mathrm{ml}$ & $4.57 \times 10^{7}$ & 1. $1.4 \%$ & $6.47 \times 10^{7}$ & $\pm 1.4 \%$ \\
\hline 9. & $\div 60$ & 60 & & 60 & \\
\hline 10 . & $\mathrm{d} / \mathrm{s} / \mathrm{m} 1 \quad \mathrm{Cs}-137$ & $7.62 \times 10^{5}$ & $\pm 1.4 \%$ & $1.08 \times 10^{6}$ & $\pm 1.4 \%$ \\
\hline & $\gamma / d=$ line $5 \div$ line 10 & $0.82 \pm 3.3 \%$ & & $0.82 \pm 3.3 \%$ & \\
\hline
\end{tabular}


A large error exists in the 0.82 gamma ray abundance from the $3 \%$ error in $\gamma / \mathrm{s}$ certified in these standards. However, where the $\mathrm{r} / \mathrm{s}$ with a $3 \%$ error is divided by 0.82 , the resulting $d / s$ is accurate to $\pm 1.4 \%$ due to cancellation of errors. Furthermore, when $d / s$ is divided by $\lambda$ corresponding to 29.2 years, the resulting atoms will be accurate to $1 \%$ because of further cancellation of errors. This accuracy, of course, applies only to this set of standards which was used to derive the 0.82 empirical factor.

Where Cs-137 analysis is performed to determine Cs-137 atom to uranium atom ratio as an indicator of uranium atom percent fission, it appears worthwhile to use a Cs-137 gamma counting standard calibrated directly in Cs-137 atom content known from isotope dilution mass spectrometry rather than one calibrated in gamma photon rate which requires the use of an accurate half-life and gamma abundance to convert to atom content. 


\section{SECTION IV}

\section{CONCLUSIONS}

The half-1ife of $\mathrm{Cs}-1.37$ has been determined to be $29.2 \pm 0.3$ years by an all mass spectrometric method. This value is in agreement with the average of the values referenced $(1-8)$ and has the smallest uncertainty. This reduces significantly the uncertainty caused by half-life in the cesium to uranium ratio method for burnup determinations. The difference from the previous half-life value determined mass spectrometrically ${ }^{(8)}$ is attributed to the greater accuracy achieved in the present work by a greater number of observations over a longer period:of time and by elimination of the need for chemical loss corrections. The abundance of the $662 \mathrm{KeV}$ gamma ray in the decay scheme of :Cs-137 was found to be $0.82 \pm 0.03$ per beta disintegration.

In the course of the work, the isotopic distribution of natural barium was determined with improved accuracy to be $(72.11 \pm 0.06) \% 138$, $(1.1 .18 \pm 0.05) \% 137,(7.77 \pm 0.02) \% 136,(6.42 \pm 0.03) \% 135,(2.33 \pm 0.02) \%$ $134,(0.091 \pm 0.003) \% 132$, and $(0.098 \pm 0.002) \% 130$. 
The authors are indebted to Dr. D. W. Gaylor for his statistical treatment of the data including an analysis of variance used in weighting the data. Gratitude is also expressed to W. E. Duffy, J. R. Asay and E. L. Kramer who made the mass spectrometric measurements reported here. 


\section{APPENDIX I}

\section{DEFINITION OF SYMBOLS. USED}

The symbols used throughout the paper are defined as follows:

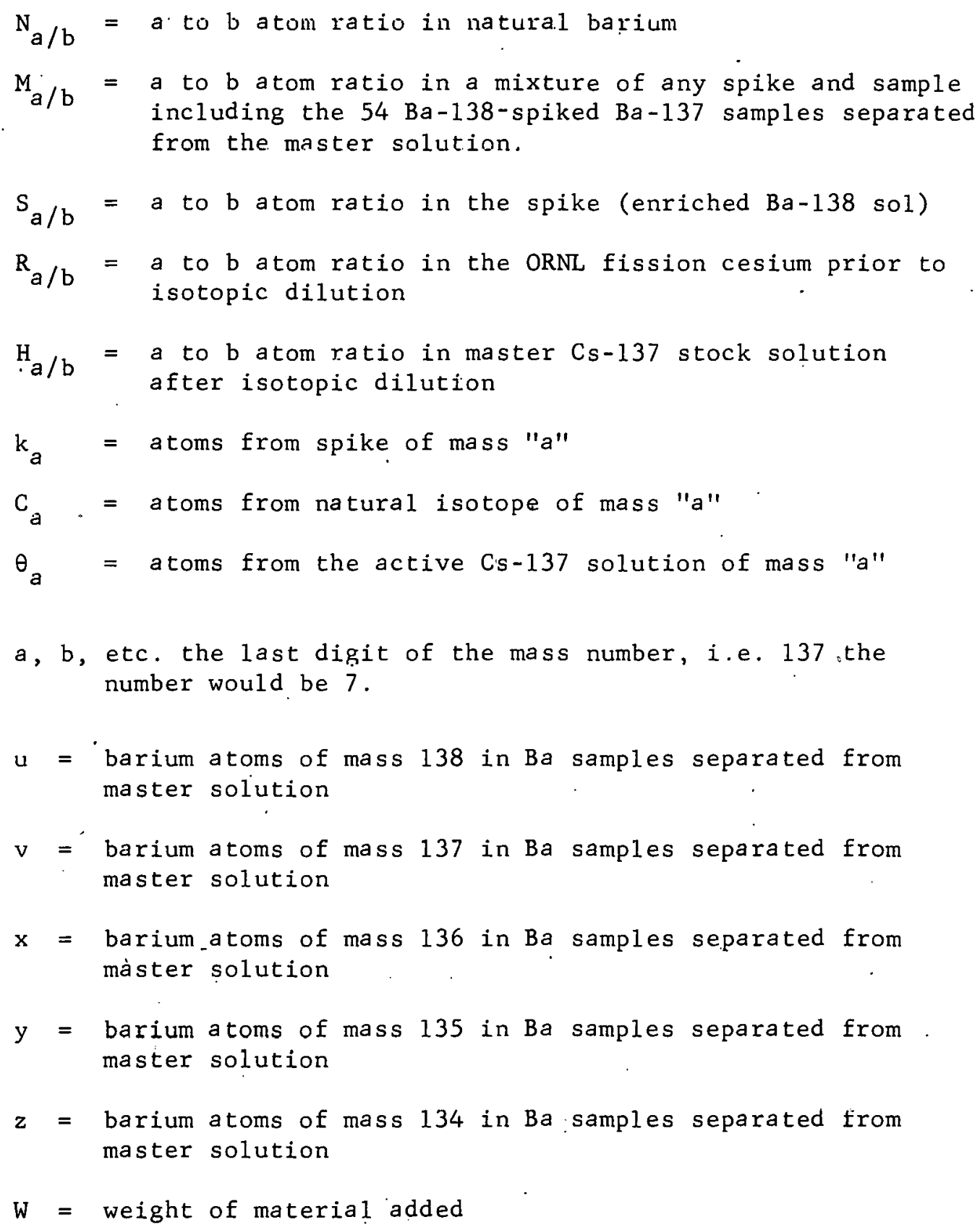




\section{APPENDIX II}

\section{CALCULATION OF THE TOTAL NUMBER OF Cs-137 ATOMS}

\section{IN THE MASTER SOLUTION}

Mass analysis was carried out on the fission cesium solution after removal of barium daughters. This solution was then added to a known weight of the natural cesium (mass-133). By using the total atoms of natural Cs-133, $C_{3}$, and ratios $R_{a / b}$ before and ratios $M_{a / b}$ after spiking, the total number of Cs-137 atoms was calculated.

$$
\begin{aligned}
& \text { Atom Cesium Ratio in Cs }-137 \text { Solution Cesium atoms added } \\
& \underline{\text { Ratio }} \\
& \text { Unspiked, } \mathrm{R}_{\mathrm{a} / \mathrm{b}} \text { Spiked, } \mathrm{M}_{\mathrm{a}} / \mathrm{b} \\
& 3 / 7 \quad 1.246 \pm 0.43 \% \quad 50.83 \pm 0.63 \% \quad 5.182 \times 10^{20} \pm 0.54 \% \\
& 3 / 5 \quad 2.505 \pm 0.36 \%, \quad 104.9 \pm 0.69 \% \\
& 7 / 5 \quad 2.061 \pm 0.73 \% \\
& \text { Atoms of } \mathrm{Cs}-137 \text { present }=C_{3} \cdot\left[\frac{1}{M_{3 / 7}-R_{3 / 7}}\right] \\
& =\frac{5.182 \times 10^{20}}{50.83-1.246} \\
& =1.045 \times 10^{19} \pm 0.84 \% \\
& \text { Atoms of Cs-137 present }=C_{3}\left[\frac{1}{M_{3 / 5}-R_{3 / 5}}\right]\left[M_{7 / 5}\right] \\
& =5.182 \times 10^{20}\left[\frac{1}{104.9-2.505}\right] 2.061 \\
& =1.043 \times 10^{19} \pm 1.16 \%
\end{aligned}
$$

By weighting these two values inversely proportional to the square of the percent error, the weighted average is obtained as follows: 


$$
\begin{aligned}
& 1.045 \times 10^{19} \times \frac{1}{(0.84)^{2}}=1.481 \times 10^{19} \\
& 1.043 \times 10^{19} \times \frac{1}{(1.16)^{2}}=0.775 \times 10^{19} \\
& \text { Total Wts. } \Rightarrow 2.160 \\
& 2.256 \times 10^{19}=\text { Sum } \\
& \text { Weighted average } \mathrm{N}_{\mathrm{Cs}-137} \quad 1.044_{4} \times 10^{19} \pm 0.68 \%
\end{aligned}
$$




\section{APPENDIX III}

\section{CALCULATION OF Ba-138 TRACER ADDED TO THE MASTER SOLUTION}

The enriched Ba-138 standard solution, designated Solution $A$, was standardized by isotopic dilution with standard natural barium chloride dihydrate solutions. The aliquots taken of both enriched and natural barium solutions were weighed in order to minimize the aliquoting error (i.e. 1.0000 gram can be weighed to \pm 0.0001 ). A weighed aliquot of the enriched barium solution was added to stock of $\mathrm{Cs}-137$. The number of Ba-138 spike atoms added, which is the value $k_{8}$ in equation 25 of Appendix IV, is obtained from the expression

$$
k_{8}=\text { (weight of Soln. A added) (atoms of Ba-138/gm of } \operatorname{Soln}_{\mathrm{v}} A \text { ) }
$$

The value of atoms of Ba-138/gm of Soln. A can be calculated from

$$
\frac{\text { Atoms } B a-138}{\text { gm of Soln A }}=C_{8}\left[\frac{\frac{M_{a / b}}{N_{a / b}}-1}{1-\frac{M_{a / b}}{S_{a / b}}}\right]
$$

where $\mathrm{C}_{8}$, is the number of natural $\mathrm{Ba}-138$ added per gm of Soln. A. The values for $\mathrm{N}_{8 / 7}, \mathrm{~N}_{8 / 6}, \mathrm{~N}_{8 / 5}, \mathrm{~N}_{8 / 4}, \mathrm{~s}_{8 / 7}, \mathrm{~s}_{8 / 6}, \mathrm{~s}_{8 / 5}$, and $\mathrm{s}_{8 / 4}$ are constants and found in Appendix $V$. The ratio $M_{a / b}$ is the only ratio which changes (a/b stands for $8 / 7,8 / 6,8 / 5$, or $8 / 4$ in succession).

The weight of Soln. A added was calculated (Equation 3b) from the weight of the $1: 100$ dilution added to the Cs-137 stock solution.

$$
\text { Wt of Soln. A added }=\frac{(w t \text {. of Soln. A) }}{(\text { diluted wt.) }} \times \begin{gathered}
\text { (wt. of dilution } \\
\text { added to Cs-137 } \\
\text { stock) }
\end{gathered}
$$




$$
\begin{aligned}
& =\frac{0.4766}{50.7012} \times 6.0158 \\
& =5.655_{5} \times 10^{-2} \pm 0.021 \% \text { gms of Soln. A } \\
& \text { added to Cs }-137
\end{aligned}
$$

Solving equation ( 1 ) for $k_{8}$, the total number of Ba-138 atoms which were added to the $\mathrm{Cs}-137$ stock is calculated, where aliquot weight of Soln. A is $5.655_{5} \times 10^{-2} \mathrm{gm}$ from equation (3b) and atoms of $\mathrm{Ba}-138$ per gm of Soln. A equals $2.078_{1} \times 10^{18}$ from Table IV on page 24 of this Appendix.

$$
\begin{aligned}
& k_{8}=\left(5.655_{5} \times 10^{-2}\right)\left(2.078_{1} \times 10^{18}\right) \\
& k_{8}=1.175_{2} \times 10^{17} \pm 0.43 \% \text { a toms Ba-138 in master } \\
& \text { Cs-137 stock. }
\end{aligned}
$$


TABLE IV

Data Calculated for Ba-138 Spike Concentration

\begin{tabular}{|c|c|c|c|c|c|c|c|c|c|}
\hline \multirow{2}{*}{ Filament } & \multicolumn{4}{|c|}{\begin{tabular}{|c|} 
Atom Ratio of \\
Spiked Barium Solution \\
\end{tabular}} & \multirow{2}{*}{$\begin{array}{c}\text { Atoms Natural Ba-138 } \\
\text { added per gm of } \\
\text { Soln. A } \\
\mathrm{C}_{8}\end{array}$} & \multirow{2}{*}{\multicolumn{4}{|c|}{ 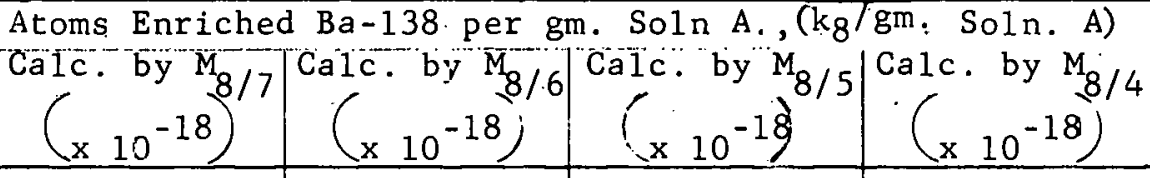 }} \\
\hline & $M_{8 / 7}$ & $\mathrm{M}_{8 / 6}$ & $M_{8 / 5}$ & $\mathrm{M}_{8 / 4}$ & & & & & \\
\hline J 583 & - & 131.8 & 178.0 & 526.9 & $1.2541 \times 10^{17}$ & - & $2.025 \pm 1.6 \%$ & $2.054 \pm 1.6 \%$ & $2.161 \pm 2.2 \%$ \\
\hline J 605 & 32.3 & 65.3 & 82.4 & - & $3.08 \mathrm{~g} 1 \times 10^{17}$ & $2.082 \pm 2.5 \%$ & $2.150 \pm 2.2 \%$ & $2.045 \pm 2.0 \%$ & - \\
\hline J 604 & 32.3 & 67.2 & 84.9 & - & $3.0891 \times 10^{17}$ & $2.082 \pm 2.5 \%$ & $2.125 \pm 3.3 \%$ & $2.120 \pm 3.6 \%$ & - \\
\hline J 606 & 36.3 & 81.3 & 105.0 & - & $2.3839 \times 10^{17}$ & $2.027 \pm 2.6 \%$ & $2.085 \pm 1.9 \%$ & $2.106 \pm 1.6 \%$ & - \\
\hline J 607 & 36.4 & 80.6 & 103.0 & - & $2.3839 \times 10^{17}$ & $2.039 \pm 3.2 \%$ & $2.062 \pm 3.0 \%$ & $2.058 \pm 4.0 \%$ & - \\
\hline J 596 & 38.8 & 91.7 & 117.5 & - & $2.0706 \times 10^{17}$ & $2.024 \pm 3.2 \%$ & $2.106 \pm 1.82 \%$ & $2.090 \pm 2.2 \%$ & - \\
\hline J 595 & 39.0 & 92.7 & 120.6 & - & $2.0706 \times 10^{17}$ & $2.047 \pm 3.6 \%$ & $2.135 \pm 2.6 \%$ & - & - \\
\hline
\end{tabular}

*Weighted as the reciprocal of the square of the error. 


\section{APPENDIX IV}

\section{DERIVATION OF EQUATIONS USED TO CALCULATE}

\section{ATOMS PRESENT IN VARIOUS SAMPLES}

Symbols used in this section are defined in Appendix I.

(a) Number of $\mathrm{Ba}-138$ Atoms, $k$, 'in Spike

The ratios measured by the mass spectrometer are:

$\mathrm{S}_{8 / 7}, \mathrm{~S}_{8 / 6}, \mathrm{~S}_{8 / 5}, \mathrm{~S}_{8 / 4}, \mathrm{~N}_{8 / 7}, \mathrm{~N}_{8 / 6}, \mathrm{~N}_{8 / 5}$, and $\mathrm{N}_{8 / 4}$.

The weight of natural barium, $W$, added to the unknown amount of a.toms of spike is known.

$$
\begin{aligned}
& \mathrm{S}_{8 / 7}=\frac{\mathrm{k}_{8}}{\mathrm{k}_{7}} \\
& \mathrm{~N}_{8 / 7}=\frac{\mathrm{C}_{8}}{\mathrm{C}_{7}} \\
& \mathrm{M}_{8 / 7}=\frac{\mathrm{k}_{8}+\mathrm{C}_{8}}{\mathrm{k}_{7}+\mathrm{C}_{7}}
\end{aligned}
$$

Solving equation ( 3 ) for ${ }^{\prime} k_{8}$

$$
k_{8}=M_{8 / 7} k_{7}+M_{8 / 7} C_{7}-C_{8}
$$

Solving equation (2) and equation (1) for $\mathrm{C}_{8}$ and $\mathrm{k}_{7}$, respectively, and substituting in equation (3a)

$$
\begin{aligned}
k_{8} & =M_{8 / 7} k_{7}+M_{8 / 7} C_{7}-N_{8 / 7} C_{7} \\
k_{8} & =\frac{M_{8 / 7} k_{8}}{S_{8 / 7}}+\left(M_{8 / 7}-N_{8 / 7}\right) C_{7}
\end{aligned}
$$




$$
\begin{aligned}
& k_{8}-\frac{M_{8 / 7} k_{8}}{S_{8 / 7}}=C_{7}\left(M_{8 / 7}-N_{8 / 7}\right) . \\
& k_{8}=\frac{C_{7}\left(M_{8 / 7}-N_{8 / 7}\right)}{\left(1-\frac{M_{8 / 7}}{S_{8 / 7}}\right)} .
\end{aligned}
$$

Where:

$$
c_{7}=\frac{W \times \text { Avogadro Number }}{\text { Molecular Wt. of Natural Barium }}\left(\begin{array}{l}
\text { Atom } \% \text { of } 137 \text { in } \\
\text { Natural Barium }
\end{array}\right)
$$

(b) Number of $\mathrm{Cs}-137$ Atoms, $k_{7}$, Present in Spike

The ratios measured by the mass spectrometer are:

$$
s_{7 / 3}, s_{7 / 5} \text {, and } s_{7 / 4} \text {. }
$$

A check of the natural cesium showed only mass 133 to be present. The sample was spiked with weight, $W$, of natural cesium.

$$
\begin{aligned}
& s_{7 / 3}=\frac{k_{7}}{k_{3}} \\
& M_{7 / 3}=\frac{k_{7}}{k_{3}+C_{3}}
\end{aligned}
$$

Solving equation (6a) for $k_{7}$

$$
k_{7}=M_{7 / 3}\left(k_{3}+c_{3}\right)
$$

Solving equation (6) for $k_{3}$ and substituting the resulting solution in equation (6a) and combining $k_{7}$ terms:

$$
k_{7}-k_{7} \frac{m_{7 / 3}}{s_{7 / 3}}=M_{7 / 3} c_{3}
$$




$$
k_{7}=c_{3} \frac{M_{7 / 3}}{1-\frac{M_{7 / 3}}{s_{7 / 3}}}
$$

Where:

$$
c_{3}=\frac{\text { W x Avogadro Number }}{\text { Molecular Wt. of Natural Cesium }}
$$

(c) Number of Ba-137 daughter atoms grown into master solution

The mass spectrometer ratios measured are:

$\mathrm{N}_{8 / 7}, \dot{\mathrm{N}}_{8 / 6}, \mathrm{~N}_{8 / 5}, \mathrm{~N}_{8 / 4}, \mathrm{M}_{8 / 7}, \mathrm{M}_{8 / 3}, \mathrm{M}_{8 / 6}, \mathrm{M}_{8 / 5}$, and $\mathrm{M}_{8 / 4}$.

Ratios $\mathrm{H}_{7 / 3}, \mathrm{~S}_{8 / 7}, \mathrm{~S}_{8 / 6}, \mathrm{~S}_{8 / 5}, \mathrm{~S}_{8 / 4}$ have been previously determined.

The general case where Cs-137 and natural barium contamination are present gives the following equation:

$$
\begin{aligned}
& M_{8 / 7}=\frac{k_{8}+c_{8}}{k_{7}+c_{7}+\theta_{7}+v} \\
& M_{7 / 3}=\frac{k_{7}+c_{7}+\theta_{7}+v}{\theta_{3}} \\
& s_{8 / 7}=\frac{k_{8}}{k_{7}} \\
& s_{8 / 6}=\frac{k_{8}}{k_{6}} \\
& H_{7 / 3}=\frac{\theta_{7}}{\theta_{3}} \\
& N_{8 / 6}=\frac{C_{8}}{C_{6}} .
\end{aligned}
$$




$$
\begin{aligned}
& M_{8 / 6}=\frac{k_{8}+C_{8}}{k_{6}+C_{6}} \\
& N_{8 / 7}=\frac{C_{8}}{C_{7}}
\end{aligned}
$$

Since the number of atoms of $\mathrm{Ba}-137$, (v), is wanted in the terms of the added $\mathrm{Ba}-138,\left(\mathrm{k}_{8}\right)$, and the ratios measured, equation (9) is solved for $v$ as follows:

$$
v=\frac{k_{8}+C_{8}-M_{8 / 7} k_{7}-M_{8 / 7} C_{7}-M_{8 / 7} \theta_{7}}{M_{8 / 7}}
$$

Equations (12) and (14) are solved for $\mathrm{k}_{6}$ and $\mathrm{C}_{6}$ and resulting solutions substituted into equation (15).

$$
M_{8 / 6}=\frac{k_{8}+C_{8}}{\frac{k_{8}}{s_{8 / 6}}+\frac{C_{8}}{N_{8 / 6}}}
$$

Solving for $\mathrm{C}_{8}$

$$
\begin{aligned}
& c_{8}=\frac{M_{8 / 6}}{S_{8 / 6}} k_{8}+\frac{M_{8 / 6}}{N_{8 / 6}} C_{8}-k_{8} \\
& c_{8}=\frac{\frac{M_{8 / 6}}{S_{8 / 6}} k_{8}-k_{8}}{\left(1-\frac{M_{8 / 6}}{N_{8 / 6}}\right)}
\end{aligned}
$$

Solving equation (16) for $\mathrm{C}_{7}$

$$
\mathrm{C}_{7}=\frac{\mathrm{C}_{8}}{\mathrm{~N}_{8 / 7}}
$$


Substituting equation (18) and (19) solutions for $C_{7}$ and $C_{8}$ into equation (17)

$$
v=\frac{k_{8}+\left[\frac{\frac{M_{8 / 6}}{S_{8 / 6}} k_{8}-k_{8}}{\left(1-\frac{M_{8 / 6}}{N_{8 / 6}}\right)}\right]-M_{8 / 7} k_{7}-C_{8} \frac{M_{8 / 7}}{N_{8 / 7}}-M_{8 / 7} \cdot \theta_{7}}{M_{8 / 7}}
$$

$$
\mathrm{v}=\frac{\mathrm{k}_{8}+\left[\frac{\frac{\mathrm{M}_{8 / 6}}{\mathrm{~S}_{8 / 6}} \mathrm{k}_{8}-\mathrm{k}_{8}}{\left(1-\frac{\mathrm{M}_{8 / 6}}{\mathrm{~N}_{8 / 6}}\right)}\right]}{\mathrm{M}_{8 / 7}}-\mathrm{k}_{7}-\frac{\mathrm{C}_{8}}{\mathrm{~N}_{8 / 7}}-\theta_{7}
$$

Substituting equation (18) in the 3 rd term and solution for $k_{7}$ from equation (11) for 2 nd term.

$$
v=\frac{k_{8}\left[1+\frac{\frac{M_{8 / 6}}{S_{8 / 6}}-1}{\left(1-\frac{M_{8 / 6}}{N_{8 / 6}}\right)}\right]}{M_{8 / 7}}-\frac{k_{8}}{S_{8 / 7}}-\frac{k_{8}}{N_{8 / 7}}\left[\frac{\frac{M_{8 / 6}}{S_{8 / 6}}-1}{1-\frac{M_{8 / 6}}{N_{8 / 6}}}\right]-\theta_{7}
$$

In order to simplify the equations, the term $\left[\frac{\frac{M_{8 / 6}}{S_{8 / 6}}-1}{1-\frac{M_{8 / 6}}{N_{8 / 6}}}\right]$

wil1 be designated by A. Equation (20) now becomes: 


$$
v=\frac{k_{8}(1+A)}{M_{8 / 7}}-\frac{k_{8}}{S_{8 / 7}}-\frac{k_{8} A}{N_{8 / 7}}-\theta_{7}
$$

Cross multiplying equation (10)

$$
M_{7 / 3} \theta_{3}=k_{7}+c_{7}+v+\theta_{7}
$$

Solving for $\theta_{3}$ in equation (13) and substituting into equation (21a) and solving for $\theta_{7}$ :

$$
\begin{aligned}
& \frac{M_{7 / 3} \theta_{7}}{H_{7 / 3}}-\theta_{7}=k_{7}+c_{7}+v \\
& \theta_{7}\left[\frac{M_{7 / 3}}{H_{7 / 3}}-1=k_{7}+c_{7}+v\right.
\end{aligned}
$$

Substituting solution for $k_{7}$ from equation (11) and $\frac{C_{8}}{N_{8 / 7}}$ for $C_{7}$ from equation (19) where $C_{8}=k_{8} A$ from equation (18)

$$
\theta_{7}\left[\frac{M_{7 / 3}}{H_{7 / 3}}-1\right]=\frac{k_{8}}{s_{8 / 7}}+\frac{k_{0} A}{N_{8 / 7}}+v
$$

In order to simplify this equation, the term $\left[\frac{\mathrm{M} / 3}{\mathrm{H} / 3}-1\right]$ will be
designated by $B$. Equation. (22) solved for $\theta_{7}$ becomes:

$$
\theta_{7}=\frac{k_{8}}{S_{8 / 7^{B}}}+\frac{k_{8} A}{N_{8 / 7^{B}}}+\frac{v}{B}
$$

Substituting equation. (23) in equation (21) and solving for $v$ 


$$
\begin{aligned}
& v+\frac{v}{B}=\frac{k_{8}(1+A)}{M_{8 / 7}}-\frac{k_{8}}{S_{8 / 7}}-\frac{k_{8}}{S_{8 / 7} B}-\frac{k_{8} A}{N_{8 / 7}}-\frac{k_{8} A}{N_{8 / 7}} \\
& v=\frac{k_{8}(1+A)}{M_{8 / 7}\left(1+\frac{1}{B}\right)}-\frac{k_{8}}{S_{8 / 7}\left(1+\frac{1}{B}\right)}-\frac{k_{8} A\left(1+\frac{1}{B}\right)}{\left(1+\frac{1}{B}\right)}-\frac{N_{8 / 7}}{\left(1+\frac{1}{B}\right)} \\
& v=k_{8}\left[\frac{\left.1+\frac{A}{M_{8 / 7}+\frac{M_{8 / 7}}{B}}-\frac{1}{S_{8 / 7}}-\frac{A}{N_{8 / 7}}\right]}{}\right.
\end{aligned}
$$

In the case where no Cs-137 correction is needed because $B$ approaches $\infty$, the equation is simplified to:

$$
v=k_{8}\left[\frac{1+A}{M_{8 / 7}}-\frac{1}{S_{8 / 7}}-\frac{A}{N_{8 / 7}}\right]
$$

The quantity $\frac{\mathrm{v}}{\mathrm{k}_{8}}$ is selected as the quantity to plot on the ordinate. against time in days on the abscissa in Figure 1. If the value of: $\frac{\mathrm{v}}{\mathrm{k}_{\mathrm{g}}}$ is multiplied by $\left(\frac{\lambda t}{1-\mathrm{e}^{-\lambda t}}\right)$ at each time, $t$, the exponential growth curve in Figure 1 becomes a straight-line function suitable for least square solution for straight-line equation in Appendix VI. 


\section{APPENDIX V}

THE CONSTANT RATIOS USED IN CALCULATIONS IN APPENDIX IV

$\begin{array}{lc}\text { Ratio } & \begin{array}{c}\text { Value Used in } \\ \text { Equations (24) and (25) }\end{array} \\ \mathrm{S}_{8 / 7} & 76.69 \pm 1.51 \\ \mathrm{~S}_{8 / 6} & 722.1 \pm 19.9 \\ \mathrm{~N}_{8 / 7} & 6.448 \pm 0.026 \\ \mathrm{~N}_{8 / 6} & 9.281 \pm 0.036 \\ \mathrm{H}_{7 / 3} & 0.01967 \pm 0.00012 \\ \frac{1}{\mathrm{~S}_{8 / 7}} & 0.01255 \pm 0.00024 \\ \frac{1}{\mathrm{~N}_{8 / 7}} & 0.1551 \pm 0.0006\end{array}$

Al1 values are arbitraily reported to four significant figures to minimize rounding errors. 


\section{APPENDIX VI}

THE Ba-137 GROWTH LINE

\section{AND WEIGHTED LEAST SQUARES SOLUTION OF ITS SLOPE}

The ratio $\frac{\text { atoms of } \mathrm{Ba}-137 \text { daughter }}{\text { atoms of } \mathrm{Ba}-138 \text { spike }}=\mathrm{v} / \mathrm{k}_{8}$ is plotted against time (in days) in Figure 1. The slope of the line was solved after the values $\frac{v}{k_{8}}$, were multiplied by $\frac{\lambda t}{1-e^{-\lambda t}}$ to correct for decrease of the atoms of $\mathrm{Cs}-137$ by decay. In the least squares solution, each $\mathrm{v} / \mathrm{k}_{8}$ point was weighted inversely as a function of the percent error. These weights are listed in the following tables. The elapsed times. -were assumed to be without error because they were known to \pm 2 minutes - or \pm 0.0014 days.

Let $s^{2}$ e denote the variance of the average among the scans for any particular point. The standard deviations, $S_{e}$, are 1 isted in the following tables for each point.

For the single stage analyses, the variance of the points from the fitted least squares line was less than the average value of $s^{2} e^{\text {. }}$ Due to the large differences in $s^{2}$ for the single stage results, weighting the points inversely proportional to $\mathrm{s}^{2}$ e would have resulted in extremely unequal weighting, whereas the precision among analyses generally do not vary markedly. Hence, the single stage points were weighted inversely proportional to $\mathrm{S}_{e}$ such that the sum of the weights equals 25 , the number of single stage points, ignoring the 1.5 multiplying factor for the moment.

For the double stage instrument, the variance of the points from the fitted least squares 1 ine was greater than the average value of $\mathrm{s}^{2}$. Hence; there was evidence of a point to point variation, $s^{2}$, in addition

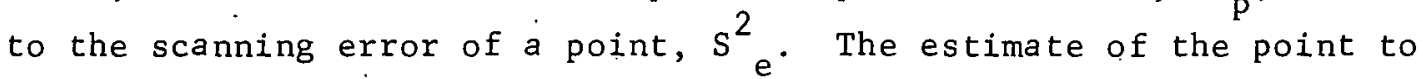
point variation was 0.00009090 . The values for $S_{p}$ are 1 isted in the 
table. The points for the double stage instrument were weighted inversely proportional to $\left(s^{2}{ }_{p}+s^{2}{ }_{e}\right)$ such that the sum of the weights equals 29 , the number of double stage points, apart from the 0.569 multiplying factor.

For either instrument, the weighted analysis did not significantly alter the slopes from their respective unweighted analyses. Hence, the choice of two different weighting procedures dictated by the different error mechanisms for the two types of spectrometers actually had no significant influence on the slope of the flnal line. The purpose of weighting was to give those points with smaller errors more weight than those points with larger errors in order to reduce the standard deviations of the estimates of the slopes for each mass spectrometer.

The slopes of the lines for the two mass spectrometers did not differ significantly, hence, it was in order to pool the data from the two instruments and obtain one line. The variance of the points about the weighted least squares 1 ine for the single stage spectrometer was 0.00003134 and 0.00008248 for the double-stage instrument. Weighting the points from the two spectrometers inversely proportional to their variances gives relative weights of 2.64 to 1.00 for single-stage and double-stage points, respectively, when pooling the data. Multiplying the weights for the individual analyses on each spectrometer by 1.500 for the single-stage instrument and by 0.569 for the double-stage instrument (see the tables) provides weighting of the combined data in the ratio of $2.64=1.500 / 0.569$ such that the sum of the weights equals , 54 , the total number of points from the two spectrometers. The weighted least squares solution for the combined data was

$$
y_{1}=\left(0.00578_{7} \pm 0.00002_{9}\right) x-\left(0.000_{5} \pm 0.001_{6}\right)
$$

where $\mathrm{y}$ is the number of $\mathrm{Ba}-137$ daughter atoms per atom of Ba-138 spike and $\mathrm{x}$ is time in days. The \pm limits are the standard deviations on the slope and intercept. The percent error of the slope is $\pm 0.5 \%$. 


\section{RESULTS FROM SINGLE STAGE INSTRUMENT}

\begin{tabular}{|c|c|c|c|c|c|c|}
\hline Sample No. & $\Delta t$ & $v / k_{8}$ & $\begin{array}{l}\text { Decay } \\
\text { Correction* }\end{array}$ & $\begin{array}{l}\text { Corrected } \\
\mathrm{v} / \mathrm{k}_{8}\end{array}$ & $\pm S_{e}^{\prime}$ & $\begin{array}{l}\text { Weight: } \\
\text { Assignea }\end{array}$ \\
\hline $\begin{array}{r}6 \\
8 \\
9 \\
11 \\
12 \\
23 \\
24 \\
27 \\
28 \\
29 \\
30 \\
31 \\
32 \\
33 \\
34 \\
35 \\
36 \\
37 \\
38 \\
39 \\
40 \\
41 \\
42 \\
43 \\
44\end{array}$ & $\begin{array}{r}6.029 \\
8.033 \\
9.755 \\
11.013 \\
12.085 \\
47.071 \\
49.042 \\
60.139 \\
61.045 \\
63.019 \\
66.031 \\
68.051 \\
69.982 \\
73.032 \\
75.057 \\
80.043 \\
84.009 \\
86.988 \\
89.040 \\
91.078 \\
97.009 \\
98.023 \\
99.994 \\
99.994 \\
99.994\end{array}$ & $\begin{array}{l}0.03566 \\
0.04762 \\
0.05881 \\
0.06121 \\
0.06948 \\
0.26667 \\
0.27803 \\
0.34784 \\
0.34381 \\
0.36754 \\
0.37155 \\
0.40611 \\
0.39670 \\
0.41563 \\
0.42973 \\
0.46992 \\
0.47944 \\
0.50690 \\
0.51256 \\
0.51556 \\
0.56317 \\
0.57493 \\
0.58567 \\
0.58506 \\
0.58171\end{array}$ & $\begin{array}{l}0.999812 \\
0.999750 \\
0.999696 \\
0.999656 \\
0.999623 \\
0.998531 \\
0.998470 \\
0.998124 \\
0.998096 \\
0.998034 \\
0.997940 \\
0.997877 \\
0.997817 \\
0.997722 \\
0.997659 \\
0.997503 \\
0.997379 \\
0.997286 \\
0.997222 \\
0.997159 \\
0.996974 \\
0.996942 \\
0.996880 \\
0.996880 \\
0.996880\end{array}$ & $\begin{array}{l}0.03566 \\
0.04763 \\
0.05883 \\
0.06123 \\
0.06951 \\
0.26706 \\
0.27846 \\
0.34849 \\
0.34446 \\
0.36826 \\
0.37232 \\
0.40697 \\
0.39757 \\
0.41657 \\
0.43074 \\
0.47110 \\
0.48070 \\
0.50828 \\
0.51399 \\
0.51703 \\
0.56487 \\
0.57669 \\
0.58750 \\
0.58689 \\
0.58353\end{array}$ & $\begin{array}{l}0.0039 \\
0.0164 \\
0.0023 \\
0.0040 \\
0.0026 \\
0.0082 \\
0.0043 \\
0.0043 \\
0.0064 \\
0.0060 \\
0.0051 \\
0.0407 \\
0.0065 \\
0.0500 \\
0.0056 \\
0.0081 \\
0.0160 \\
0.0104 \\
0.0081 \\
0.0098 \\
0.0226 \\
0.0282 \\
0.0081 \\
0.0081 \\
0.0084\end{array}$ & $\begin{array}{l}1.68 \times 1.5 \\
0.40 \times 1.5 \\
2.83 \times 1.5 \\
1.63 \times 1.5 \\
2.51 \times 1.5 \\
0.80 \times 1.5 \\
1.52 \times 1.5 \\
1.52 \times 1.5 \\
1.02 \times 1.5 \\
1.09 \times 1.5 \\
1.28 \times 1.5 \\
0.16 \times 1.5 \\
1.01 \times 1.5 \\
0.13 \times 1.5 \\
1.17 \times 1.5 \\
0.81 \times 1.5 \\
0.41 \times 1.5 \\
0.63 \times 1.5 \\
0.81 \times 1.5 \\
0.67 \times 1.5 \\
0.29 \times 1.5 \\
0.23 \times 1.5 \\
0.81 \times 1.5 \\
0.81 \times 1.5 \\
0.78 \times 1.5\end{array}$ \\
\hline \multicolumn{5}{|c|}{$\begin{array}{l}\text { Values Indicated are the reciprocal of } \lambda t\left(i-e^{-\lambda t}\right) \text { described } \\
\text { text and are divided into v/k to correct for decay. }\end{array}$} & Total & $25.00 \times 1.5$ \\
\hline
\end{tabular}


RESULTS FFOM DOUBLE STAGE INSTRUMENT

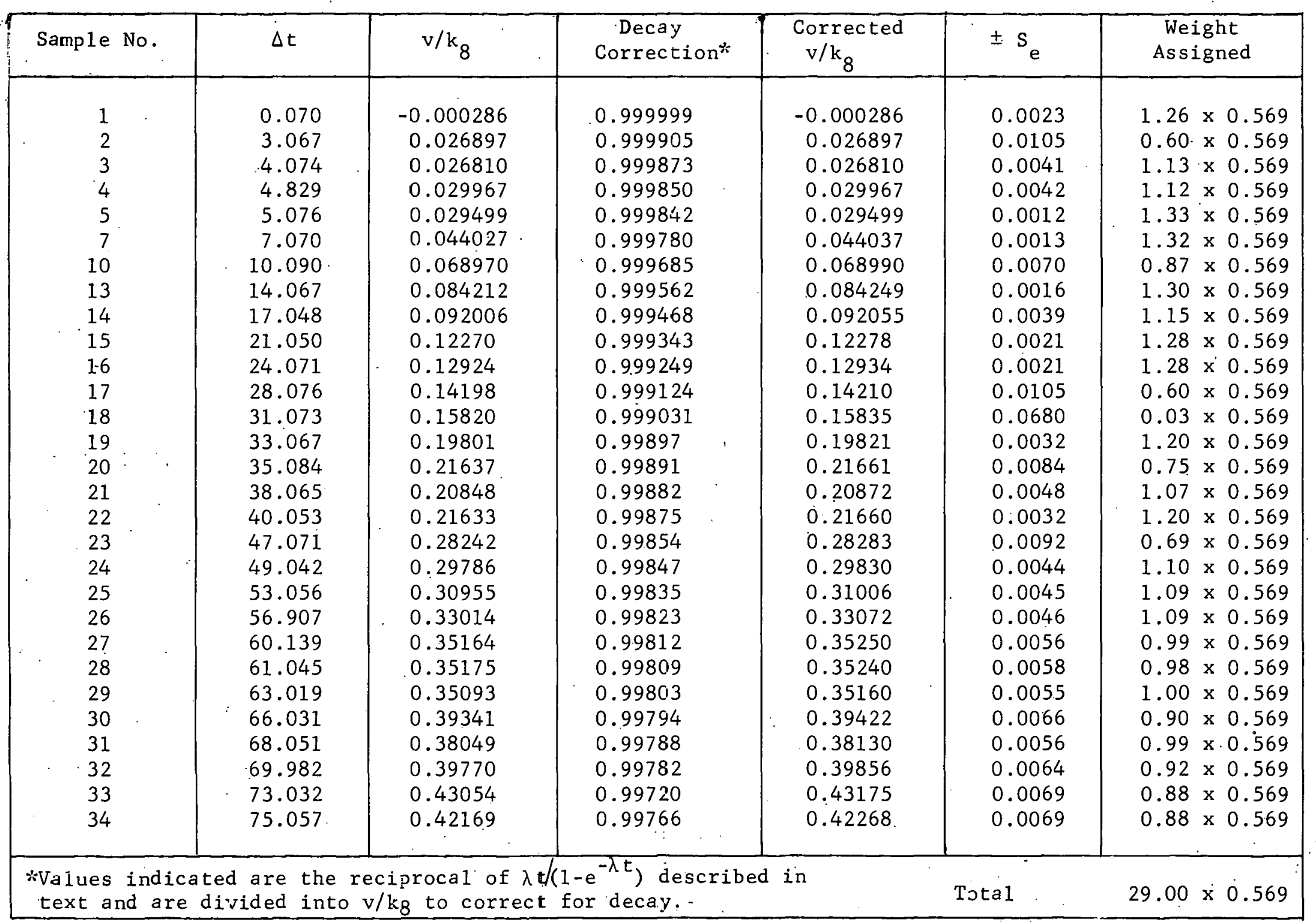


The weighted least squares solution used the following equations.

$$
y=a x+b
$$

where

$$
\begin{aligned}
& y=v / k_{8} \\
& x=t \\
& a=\text { slope } \\
& b=y \text { intercept }
\end{aligned}
$$

Assuming no error in $\underline{x}$ and all errors to. be in $y$, the least square solution becomes:

$$
\begin{aligned}
& . a=\frac{\sum(w t) \Sigma(w t)(x y)-\Sigma(w t)(x) \Sigma(w t)(y)}{\Sigma(w t) \Sigma(w t)\left(x^{2}\right)-[\Sigma(w t)(x)]^{2}} \\
& b=\frac{\sum(w t)\left(x^{2}\right) \Sigma(w t)(y)-\Sigma(w t)(x) \Sigma(w t)(x y)}{\Sigma(w t) \Sigma(w t)\left(x^{2}\right)-[\Sigma(w t)(x)]^{2}}
\end{aligned}
$$




\title{
APPENDIX VंII
}

\section{CALCULATION OF GAMMA-RAY ABUNDANCE IN THE DECAY OF Cs-137}

\begin{abstract}
Aliquots of the master Cs-137 stock solution were weighed and sealed in vials of the same dimensions as the Nuclear Chicago Cs-137 vials. The sample vials were then counted on low geometry shelves $5,6,7$, and 9 corresponding to a sample to sodium iodide crystal distance of 49.3,69.7, 100.2 and $145.7 \mathrm{~cm}$., respectively, and on two different analyzers in comparison with two different Nuclear Chicago Cs-137 standards. The following data were obtained for the $\mathrm{r} / \mathrm{m}$ at $662 \mathrm{Kev}$ corrected to the total weight of the master Cs-137 stock solution.
\end{abstract}


SUMMARY OF COUNTING DATA

\begin{tabular}{|c|c|c|c|}
\hline Ampoule & Shelf & $\begin{array}{c}\text { RCL 256-Channel } \\
\mathrm{r} / \mathrm{m} \times 10^{-11}\end{array}$ & $\begin{array}{l}\text { RIDL 200-Channe'1 } \\
\mathrm{r} / \mathrm{m} \times 10^{-11}\end{array}$ \\
\hline \multirow[t]{2}{*}{ A } & 9 & $\begin{array}{l}--- \\
--- \\
-- \\
-- \\
-- \\
\end{array}$ & $\begin{array}{r}3.950 \\
3.952 \\
3.886 \\
3.890 \\
3.887 \\
\end{array}$ \\
\hline & 7 & --- & $\begin{array}{r}3.868 \\
3.877 \\
\end{array}$ \\
\hline \multirow[t]{3}{*}{ B } & 9 & $\begin{array}{l}--- \\
--- \\
--- \\
--- \\
--- \\
\end{array}$ & $\begin{array}{r}4.180 \\
4.275 \\
. \quad 3.749 \\
\therefore \quad 3.900 \\
3.909 \\
\end{array}$ \\
\hline & 7 & $\begin{array}{l}-- \\
--- \\
\end{array}$ & $\begin{array}{l}3.895 \\
3.910 \\
\end{array}$ \\
\hline & .6 & $\begin{array}{l}4.010 \\
3.901 \\
3.846\end{array}$ & \\
\hline \multirow{4}{*}{ C } & 9 & $\begin{array}{l}-- \\
--- \\
--\end{array}$ & $\begin{array}{l}4.041 \\
3.962 \\
3.872\end{array}$ \\
\hline & 7 & $\cdots$ & $\begin{array}{l}3.885 \\
3.869\end{array}$ \\
\hline & 6 & $\begin{array}{l}3.854 \\
3.856\end{array}$ & 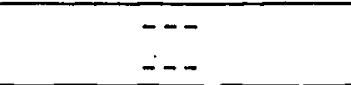 \\
\hline & 5 & 3.573 & --- \\
\hline \multirow{4}{*}{$D$} & 9 & $\begin{array}{l}--- \\
--- \\
-\therefore- \\
\end{array}$ & $\begin{array}{l}3.914 \\
3.901 \\
3.846\end{array}$ \\
\hline & 7 & $\begin{array}{l}-- \\
--- \\
\end{array}$ & $\begin{array}{l}3.899 \\
3.894 \\
\end{array}$ \\
\hline & 6 & $\begin{array}{l}3.814 \\
3.842 \\
\end{array}$ & --- \\
\hline & 5 & $\begin{array}{l}3.814 \\
3.814 \\
\end{array}$ & $\begin{array}{l}+\cdots \\
\cdots--\end{array}$ \\
\hline \multirow{4}{*}{$\mathrm{E}$} & 9 & $\begin{array}{c}- \\
--- \\
-\ldots\end{array}$ & $\begin{array}{l}3.952 \\
3.915 \\
3.900\end{array}$ \\
\hline & 7 & $\begin{array}{l}-- \\
--- \\
\end{array}$ & $\begin{array}{r}3.903 \\
3.913 \\
\end{array}$ \\
\hline & 6 & $\begin{array}{l}3.828 \\
3.864 \\
3.825 \\
3.841 \\
\end{array}$ & $\begin{array}{l}--- \\
--- \\
--- \\
---\end{array}$ \\
\hline & 5 & 3.883 & -- \\
\hline
\end{tabular}


SUMMARY OF COUNT ING DATA (continued)

\begin{tabular}{|c|c|c|c|}
\hline Ampoule & Shelf & $\begin{array}{c}\text { RCL 256-Channel } \\
\mathrm{r} / \mathrm{m} \times 10^{-11}\end{array}$ & $\begin{array}{c}\text { RIDL 200-Channe1 } \\
\mathrm{r} / \mathrm{m} \times 10^{-11}\end{array}$ \\
\hline \multirow{4}{*}{$\mathrm{F}$} & 9 & $\begin{array}{l}- \\
- \\
-\end{array}$ & $\begin{array}{l}3.896 \\
3.878 \\
3.886\end{array}$ \\
\hline & 7 & $\begin{array}{l}3.711 \\
3.740 \\
3.769\end{array}$ & $\begin{array}{r}3.894 \\
3.897 \\
\ldots\end{array}$ \\
\hline & 6 & $\begin{array}{l}3.786 \\
3.789 \\
3.813 \\
3.764\end{array}$ & $\begin{array}{l}-- \\
-- \\
-- \\
--\end{array}$ \\
\hline & 5 & $\begin{array}{l}3.788 \\
3.772 \\
3.801 \\
\end{array}$ & $\begin{array}{l}--1 \\
-- \\
- \\
\end{array}$ \\
\hline \multirow{4}{*}{ G } & 9 & $\begin{array}{l}-- \\
-- \\
--\end{array}$ & $\begin{array}{l}3.977 \\
3.948 \\
3.866\end{array}$ \\
\hline & 7 & $\begin{array}{l}3.721 \\
3.906\end{array}$ & $\begin{array}{l}3.902 \\
3.883 \\
\end{array}$ \\
\hline & 6 & $\begin{array}{l}3.817 \\
3.809 \\
\end{array}$ & $\begin{array}{l}-- \\
-- \\
\end{array}$ \\
\hline & 5 & 3.821 & -- \\
\hline
\end{tabular}

\begin{tabular}{cr} 
Sample & $\begin{array}{r}\text { Average Value } \\
\text { of } \gamma / \mathrm{m} \text { Cs }-137\end{array}$ \\
\hline A & $3.901 \times 10^{11}$ \\
B & $3.958 \times 10^{11}$ \\
C & $3.864 \times 10^{11}$ \\
D & $3.860 \times 10^{11}$ \\
E & $3.882 \times 10^{11}$ \\
F & $3.812 \times 10^{11}$ \\
G & $3.865 \times 10^{11}$ \\
\hline
\end{tabular}

Grand Average $\overline{3.877 \times 10^{11}} \pm 3.2 \%$

(of which $3 \%$ is uncertainty in $\mathrm{N}-\mathrm{C}$ Std.)

The $662 \mathrm{Kev}$ gamma abundance per beta disintegration of Cs-137 is expressed as:

$$
\text { gamma abundance }=\frac{r / \mathrm{mCs}-137}{\left(\text { atoms Cs-137) }\left(\lambda \mathrm{min}^{-1}\right)\right.}
$$


Since atoms of Cs-137 present $=1.0444 \times 10^{19}$ (See Appendix II), $\lambda=4.521 \times 10^{-8} \mathrm{~min} .^{-1}$, and $\gamma / \mathrm{m} \mathrm{Cs}-137=3.877 \times 10^{11}$, gamma abundance $=\frac{3.877 \times 10^{11} \pm 3.2 \%}{1.0444 \times 10^{19} \pm 0.68 \% \times 4.521 \times 10^{-8} \pm 1 \%}=0.82 \pm 3 ! 3 \%$. 


\section{REFERENCES}

1. Rider, B. F., Russe11, J. L., Jr., Harris, D. W., and Peterson, J. P., Jr., AEC-Doc. GEAP-3373 (1960), p. 20.

2. Wiles, D. M., and Tomlinson, R. H., Phys. Rev. $\underline{99}$ (1955), p. 188.

3. Brown, F., Hall, G. R., and Walter, A. J., J. Inorg. and Nuc. Chem. 1, (1955), p. 241.

4. Moses, A. J., and Cook, H. D., AEC Doc. TID-7568 (Pt. 2) (1958), p. 192 .

5. Glendenin, L. E., and Steinberg, E. P., Private communication (1960), reported in Reference 8 , below.

6. Butler, T. A., Radioisotopes Catalog, 3rd Rev., Oak Ridge National Laboratory, Oak Ridge, Tennessee (1960) p. 87, footnote 2 .

7. Glazunov, M. P., Grivkova, A. I., Zaitsev, B. A., and Kiselev, V. A., Atomnaya Energ., 10 (1961) p. 622

8. Farrar, H., Dasgupta, A. K., and Tomlinson, R. H., Can. J. Chem., 39 (1961) p. 681 